\title{
The Effect of Music on Brain Activity an Emotional State ${ }^{\dagger}$
}

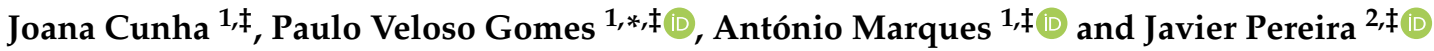 \\ 1 LabRP-CIR, Psychosocial Rehabilitation Laboratory, Center for Rehabilitation Research, School of Health, \\ Polytechnic Institute of Porto, 4200-465 Porto, Portugal; 10160312@ess.ipp.pt (J.C.); \\ ajmarques@ess.ipp.pt (A.M.) \\ 2 CITIC, Research Center of Information and Communication Technologies, Talionis Research Group, \\ Universidade da Coruña, 15071A Coruña, Spain; javier.pereira@udc.es \\ * Correspondence: pvg@ess.ipp.pt \\ + Presented at the 4th XoveTIC Conference, A Coruña, Spain, 7-8 October 2021. \\ $\ddagger$ These authors contributed equally to this work.
}

\section{check for}

updates

Citation: Cunha J.; Gomes P.; Marques A.; Pereira J. The Effect of Music on Brain Activity an Emotional State. Eng. Proc. 2021, 7, 19. https:// doi.org/10.3390/engproc2021007019

Academic Editors: Joaquim de Moura, Marco A. González, Javier Pereira and Manuel G. Penedo

Published: 11 October 2021

Publisher's Note: MDPI stays neutral with regard to jurisdictional claims in published maps and institutional affiliations.

Copyright: (c) 2021 by the authors. Licensee MDPI, Basel, Switzerland. This article is an open access article distributed under the terms and conditions of the Creative Commons Attribution (CC BY) license (https:// creativecommons.org/licenses/by/ $4.0 /)$.

\begin{abstract}
This study explores the potential of music as a therapy element in digital therapy programs to improve mental health and well-being. Music induces an emotional component in the individual that translates into changes in their brain activity, which can be monitored through electroencephalography. A scoping review was conducted to identify the most recent relevant publications related to the effect of music on brain activity and emotional state in digital therapy programs. From 585 identified publications, six relevant publications were selected that meet all the requirements defined in the study.
\end{abstract}

Keywords: music; emotions; brain activity; electroencephalography

\section{Introduction}

The influence of music on brain activity and emotional state is a topic that has gained relevance due to its potential application in therapeutic programs with clear benefits for patients. The sound, rhythm, time, intensity, and frequency of the music can induce different types of positive or negative emotions. Music can generate positive and negative emotions, and its effect may vary from person to person [1].

The emotional impact provided by music can be gauged by performing measurements of brain signals through the EEG, allowing us to relate the emotions felt to the music that triggered them [2].

A scoping review was carried out to identify the most recent relevant publications related to the effect of music on brain activity and emotional state in digital therapies programs, selecting a set of studies from the last 5 years.

\section{Materials and Methods}

The present scoping review was conducted in conformity with the Joanna Briggs Institute (JBI) and PRISMA method guidelines to identify the most recent relevant publications related to the effect of music on brain activity and emotional state in digital therapies programs. To ensure a comprehensive number of documents with significant evidence for the intended analysis, the research equation was elaborated: music AND (electroencephalography OR electroencephalogram OR EEG) AND emotion* AND ("digital therapies" OR "digital therapy" OR "digital treatment"). The research was carried out in scientific databases B-On, Google Scholar and Semantic Scholar, during May of 2021.

\section{Results}

The study flow diagram is presented in Figure 1. Initially, a sample of 585 documents were collected, and after removing the duplicates, 570 documents were obtained. After analyzing each document based on the theme and summary, the sample was reduced to 
180 selected articles. Subsequently, and after applying the inclusion criteria, a sample of six articles were obtained to be mapped.

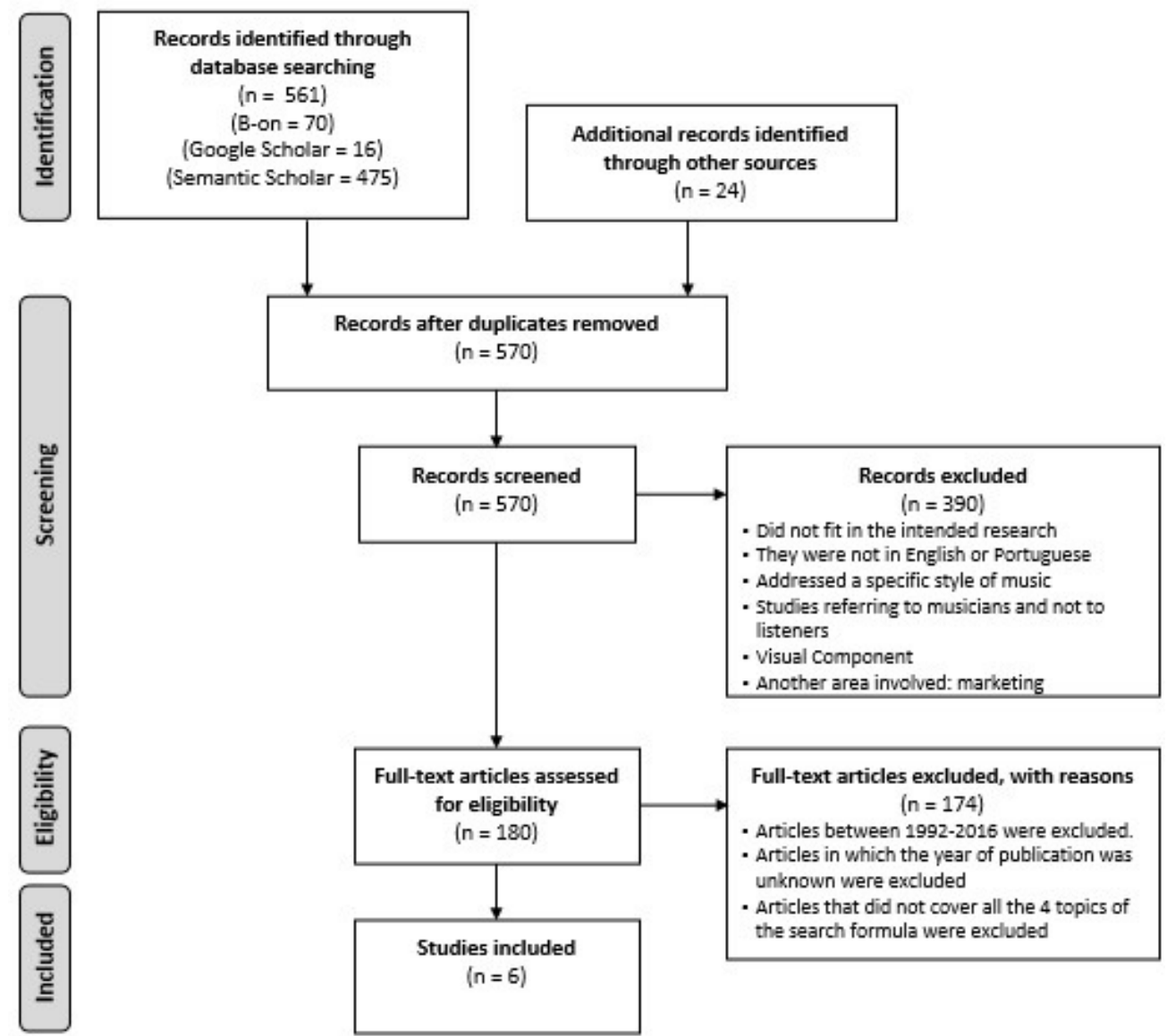

Figure 1. Preferred Reporting Items for Systematic Reviews and Meta-Analyses (PRISMA) flow diagram for the scoping review process. Adapted from Moher D, Liberati A, Tetzlaff J, Altman DG: The PRISMA Statement. PLoS Med 6(7): e1000097. https:/ / doi.org/10.1371/journal.pmed.1000097.

From Table 1, it is possible to analyze the selected documents that correspond to all the requirements defined in the research process.

Table 1. Mapping of scientific articles based on requirements defined in the study.

\begin{tabular}{ll}
\hline Reference & Abstract \\
\hline Dutta et al., 2020 [3] & $\begin{array}{l}\text { The electroencephalogram allows to understand the impact } \\
\text { of music, through the emotions felt and the registered signal. } \\
\text { The prolonged influence of negative emotions leads to mental } \\
\text { illnesses such as anxiety or depression. This article allowed to } \\
\text { develop a music playlist. }\end{array}$ \\
\hline Lee et al., 2020 [4] & $\begin{array}{l}\text { This article implements a music recommendation system to } \\
\text { provide users with a list of emotions according to different } \\
\text { symptoms. Through a combination of algorithms, is possible } \\
\text { to carry out a survey of different types of music, to achieve a } \\
\text { music therapy system aimed at treating depression. }\end{array}$ \\
\hline
\end{tabular}


Table 1. Cont.

\begin{tabular}{ll}
\hline Reference & Abstract \\
\hline Ramirez et al., 2018 [5] & $\begin{array}{l}\text { This article evaluated, based on an electroencephalographic record- } \\
\text { ing, the emotional response of patients with end-stage cancer to a } \\
\text { music therapy (MT) intervention in a randomized clinical trial. Sub- } \\
\text { sequently, emotional indicators were extracted to quantify the overall } \\
\text { effect of MT on patients compared to controls and the relative effect } \\
\text { of the different MT techniques applied during each session. }\end{array}$ \\
\hline Schaefer, 2017 [6] & $\begin{array}{l}\text { This article investigated the emotions evoked by music, and their } \\
\text { potential as a therapy. The tomographies performed allowed to un- } \\
\text { derstand which areas of the brain are activated by musical stimuli.It } \\
\text { was also discovered that the blocking of a specific class of receptors } \\
\text { can be a mechanism for the treatment of certain psychiatric or neuro- } \\
\text { logical diseases associated with music, with neurochemical studies } \\
\text { being an aspect to be considered. }\end{array}$ \\
\hline Soontreekulpong et al., & $\begin{array}{l}\text { This article investigated the relationship between the effects of three } \\
\text { musical beats: slow, normal and fast, with the major mode and the } \\
\text { electroencephalogram beta index for negative emotion reduction. } \\
\text { Stroop color tests were used to induce stress in some participants. } \\
\text { The results shows when the musical rhythm was normal, it was } \\
\text { more effective in decreasing beta activity in the right frontal region } \\
\text { compared to the others, proving that music is one of the resources for } \\
\text { reducing negative emotion. }\end{array}$ \\
\hline $\begin{array}{l}\text { In this study, after subjecting some individuals to electroencephalo- } \\
\text { graphic recording while listening to music, to have a direct effect on } \\
\text { people's emotions, it was possible to verify that there was significant } \\
\text { activity in five different regions of the brain. }\end{array}$ \\
\hline Turrell et al., 2019 [8]
\end{tabular}

\section{Discussion and Conclusions}

In this scoping review, the authors identified six recent and relevant publications related to the effect of music on brain activity and emotional state in digital therapy programs. To cover the concepts that involve the subject of the study, four research terms were defined: "Music", "Electroencephalography", "Emotion" and "Digital Therapies".

This study identified relevant publications that describe very revealing studies on the importance of music as a therapeutic element in mental health and well-being areas.

Author Contributions: Conceptualization, J.C., P.V.G.; methodology, J.C., P.V.G.; validation, P.V.G.; investigation, J.C.; writing—original draft preparation, J.C.; writing—review and editing, J.C., P.V.G.; visualization, J.C., P.V.G.; supervision, A.M., J.P.; project administration, J.C. All authors have read and agreed to the published version of the manuscript.

Funding: This research received no external funding.

Acknowledgments: This research was carried out and used the equipment of the Psychosocial Rehabilitation Laboratory (LabRp) of the Research Center in Rehabilitation of the School of Allied Health Technologies, Polytechnic Institute of Porto.

Conflicts of Interest: The authors declare no conflict of interest.

\section{References}

1. Hausmann, M.; Hodgetts, S.; Eerola, T. Music-induced changes in functional cerebral asymmetries. Brain Cogn. $2016,104,58-71$. [CrossRef] [PubMed]

2. Daly, I.; Williams, D.; Hallowell, J.; Hwang, F.; Kirke, A.; Malik, A.; Nasuto, S.J. Music-induced emotions can be predicted from a combination of brain activity and acoustic features. Brain Cogn. 2015, 101, 1-11. [CrossRef] [PubMed]

3. Dutta, E.; Bothra, A.; Chaspari, T.; Ioerger, T.; Mortazavi, B.J. Reinforcement Learning using EEG signals for Therapeutic Use of Music in Emotion Management. In Proceedings of the 2020 42nd Annual International Conference of the IEEE Engineering in Medicine \& Biology Society (EMBC), Montreal, QC, Canada, 20-24 July 2020; pp. 5553-5556. 
4. Lee, S.; Chen, T.; Hsien, Y.; Cao, L. A Music Recommendation System for Depression Therapy Based on EEG. In Proceedings of the 2020 IEEE International Conference on Consumer Electronics-Taiwan (ICCE-Taiwan), Taoyuan, Taiwan, 28-30 September 2020.

5. Ramirez, R.; Planas, J.; Escude, N.; Mercade, J.; Farriols, C.; Kenny, D.T. EEG-Based Analysis of the Emotional Effect of Music Therapy on Palliative Care Cancer Patients. Front. Psychol. 2018, 9, 1-7. [CrossRef] [PubMed]

6. Schaefer, H. Music-Evoked Emotions-Current Studies. Front. Neurosci. 2017, 11, 1-27. [CrossRef] [PubMed]

7. Soontreekulpong, N.; Jirakittayakorn, N.; Wongsawat, Y. Investigation of Various Manipulated Music Tempo for Reducing Negative Emotion Using Beta EEG Index. In Proceedings of the 2018 International Electrical Engineering Congress (IEECON), Krabi, Thailand, 7-9 March 2018; pp. 1-4.

8. Turrell, A.; Halpern, A.R.; Javadi, A. When tension is exciting: An EEG exploration of excitement in music. bioRxiv 2019, [CrossRef] 